\title{
Micro-Faraday cup array structures fabrication in silicon using deep reactive ion etching
}

\section{Julfekar Arab* and Pradeep Dixit}

Mechanical Engineering Department, Indian Institute of Technology Bombay,

Powai, Mumbai 400076, India

Email: arabjulfekar@gmail.com

Email: Pradeep.dixit@iitb.ac.in

*Corresponding author

\section{P.K. Brahmankar and Raju S. Pawade}

Mechanical Engineering Department,

Dr. Babasaheb Ambedkar Technological University, Lonere, Raigad, Maharashtra 402103, India

Email: pkbrahma@yahoo.com

Email: raju_s_pawade@yahoo.com

\section{Arvind K. Srivastava}

Indus Synchrotron Utilization Department,

Raja Ramanna Center for Advanced Technology,

Indore 452013, India

Email: sarvind@rrcat.gov.in

\begin{abstract}
Micro-Faraday cup array (MFCA) detectors are used for the detection and analysis of incident ion particles with greater stability and precision. New and simple micro FCA structures have been designed and fabricated considering the application in mass spectrometry and laser plasma techniques. MFCA structures were fabricated using UV lithography followed by deep reactive ion etching (DRIE). The UV lithography process was utilised for fabrication of micro-Faraday cup array structure in photoresist (AZ4903) deposited on n-type silicon substrate. After that DRIE process was used for creating array pattern in silicon. Ultimately $1 \times 16$ arrays having $25 \mu \mathrm{m}$ widths with $125 \mu \mathrm{m}$ spacing were fabricated. Maximum depth achieved with DRIE process was $16 \mu \mathrm{m}$. Exposure time of lithography was found to be reduced by $110 \%$ using UV-LED source for these structures. Effects of etch cycle time on cup depth and sidewall angle have also been discussed.
\end{abstract}

Keywords: Faraday cups; micro-fabrication; structural characterisation; UV-LED; deep reactive ion etching; DRIE; mass spectrometry.

Reference to this paper should be made as follows: Arab, J., Dixit, P., Brahmankar, P.K., Pawade, R.S. and Srivastava, A.K. (2020) 'Micro-Faraday cup array structures fabrication in silicon using deep reactive ion etching', Int. J. Precision Technology, Vol. 9, No. 1, pp.37-55. 
Biographical notes: Julfekar Arab received his BE in Mechanical Engineering from the Walchand Institute of Technology Solapur and MTech in Manufacturing Engineering from the Dr. Babasaheb Ambedkar Technological University, Lonere, Maharashtra in 2012 and 2015, respectively. He is currently pursuing his $\mathrm{PhD}$ from the Indian Institute of Technology, Bombay, Mumbai and presently associated with research work related to non-conventional micro-machining processes.

Pradeep Dixit is an Assistant Professor in Mechanical Engineering Department, I.I.T. Bombay. He received his BE in Mechanical Engineering from the M.M.M. University of Technology and MTech from the I.I.T. Bombay. He received his $\mathrm{PhD}$ from the Nanyang Technological University, Singapore in 2008. His research interest is in MEMS packaging and electro-chemical micro-machining.

P.K. Brahmankar is a Professor and the Head in Mechanical Engineering Department at the Dr. Babasaheb Ambedkar Technological University, Lonere, Raigad. He received his National Merit Scholarship and BTech in Mechanical Engineering from the College of Engineering, Pune in 1980. He received his MTech in Production Engineering from the IIT Delhi and PhD from the IIT Bombay. His areas of interest include machining, composite materials and metrology.

Raju S. Pawade is an Associate Professor in Mechanical Engineering Department at the Dr. Babasaheb Ambedkar Technological University, Lonere, Raigad. He received his BE in Mechanical Engineering from the College of Engineering Karad and ME in Machine Tool Engineering from the PSG Tech Coimbatore in 1989 and 1997, respectively. He received his PhD from the IIT Bombay in 2008. His research interests are in machining of difficult to cut materials, machining optimisation and surface integrity. He has published over 130 research papers in international conferences and journals.

Arvind K. Srivastava is a Scientific Officer in Indus Synchrotron Utilization Division, Raja Ramanna Center for Advanced Technology, Indore. He received his BSc, MSc and PhD in Physics from the Banaras Hindu University, Varanasi in year 1987, 1989 and 1995 respectively. His research interests are in materials science and micro-fabrication.

This paper is a revised and expanded version of a paper entitled 'Micro-fabrication of Faraday cup array structures in silicon using DRIE' presented at 6th International and 27th All India Manufacturing Technology, Design and Research Conference (AIMTDR-2016), College of Engineering, Pune, Maharashtra, India, 16-18 December 2016.

\section{Introduction}

Conventional Faraday cup is the basic and classical type of ion detector used in the ion mass spectroscopy, electron microscopy, wave tube guns and laser-plasma technologies (Prokupek et al., 2014; Birkinshaw, 2002). Faraday cup ion detectors have been used in ion mobility spectrometry which has defence applications related to detection of explosives and chemicals (Eiceman et al., 2004). These ion detectors have typical cylindrical cup structure with dimensions in few $\mathrm{mm}$. The flux of incoming charged 
particles based on their 'mass and charge' is to be calculated using this detector. Once ions have been separated according to their 'mass and charge' values by the mass analyser, they are detected. Thereafter, the resulting signals are amplified and stored (Darling et al., 2002).

In order to improve resolution, ion collection efficiency and to reduce ions detection loss, the miniaturised array form of Faraday cups are developed. They are termed as Micro-faraday cup array (FCA). They are in an array form ranging from $1 \times 16$ to $1 \times 256$ (Darling et al., 2002; Bower et al., 2007). Since these are multiple cups, it requires multiple circuitries for charge measurement to acknowledge the response from every cup. In order to get the response from each cup, FCA structures are to be formed as metal-oxide-semiconductor (MOS). By making MOS structure, it is possible to store and detect charge from every cup one by one. These micro FCA structures are designed based on the radius of deflection of incoming ions. The radius of deflection of the incoming charged particles (ions) is that radius through which the ions deflect while travelling towards the Faraday cups.

Literature review on the past work in the area of design and micro-fabrication techniques for micro-Faraday cup array (MFCA) structure was carried out. It is observed that variety of designs of Faraday cup arrays have been fabricated and tested for different applications in various devices.

Lorincik et al. (2011) have developed MFCA having 32 thin film strip electrodes and they successfully tested them in secondary ion mass spectrometry. Secondary ions such as $\mathrm{Si}, \mathrm{SiH}, \mathrm{O}, \mathrm{SiD}, \mathrm{OD}$, etc., were generated and measured with this thin film-based MFCA detectors under the application incident $\mathrm{O}_{2}$ primary ions on silicon substrate.

Prokupek et al. (2014) developed arrays of two concentric cylinders which are arranged in angular fashion. These Faraday cup array detectors were used for calculating space distribution of current density of laser-plasma systems.

Darrow et al. (2010) have used a thin foil Faraday cup detector array for loss investigative study of $\mathrm{MeV}$ alpha particles from plasmas under the application of helium neutral beam ions heating. The film thickness of the foil Faraday cups varied from $2.5 \mu \mathrm{m}$ to $4 \mu \mathrm{m}$.

Bower et al. (2007) micro-fabricated dense one-dimensional arrays of FCA of 64 cups having cup width ranging from $15 \mu \mathrm{m}$ to $45 \mu \mathrm{m}$ using UV-lithography and DRIE in silicon substrate. They measured the cup-to-ground capacitance values of the fabricated MFCAs; which were quite close to predicted values.

Darling et al. (2002) have developed MFCA by DRIE process with 64 to 256 arrays in silicon (n-type). The pitch used between two cups is 150 to $250 \mu \mathrm{m}$. They have developed linear parallel cup trenches in silicon wafer with aspect ratio around 2:1. These MFCA detectors were utilised in miniature mass spectrometer for testing purpose. They found that sensitivity of electronic readout improved by a factor approximately equals to no. of arrays. Knight et al. (2002) fabricated FCA structures with width of $145 \mu \mathrm{m}$ and $1.6 \mathrm{~mm}$ long structure in silicon (n-type), with spacing of around $100 \mu \mathrm{m}$ having 256 arrays. These MFCA detectors were successfully tested by exposing to low flux $\mathrm{Ar}^{+}$ ion beam. MFCA detectors show less crosstalk between adjacent array elements. Scheidemann et al. (2002) developed a Faraday cup detector, which was one dimensional having $9 \mathrm{~mm}$ width and $12 \mathrm{~mm}$ length. They used 256 arrays in their design. They also fabricated $8 \times 8$ circular arrays in $700 \mu \mathrm{m}$ thick silicon and copper substrate. 
Micro features in material can be created using various techniques such as MEMS micro-fabrication process (Madou, 2012), electro-chemical process (Anasane and Bhattacharyya, 2016), electro-discharge process (Jain et al., 2015) and mechanical abrasion processes (Gopikrishnan et al., 2015; Kumar et al., 2017). For the fabrication of micro-Faraday cup structures on silicon substrate, the lithography technique and etching process are essential (Mahalik, 2008; Qu, 2016). Micro-features in silicon can be fabricated by either wet etching or by dry (plasma) etching. Structures obtained in wet etching are generally isotropic though it has high etch rate. Undercut issue is dominant in case of wet etching as etchants are prone to remove substrate material under the mask material. Etching rate varies with prolonged usage of etchant chemical (Kovacs et al., 1998). Reactive ion etching (RIE) is also known as plasma etching or dry etching combines chemical and physical effects to remove material from the wafer surface $(\mathrm{Ou}$ et al., 2010). Anisotropic features can be generated using dry etching. Hence, dry etching is the mostly used for creating features with exact $90^{\circ}$, vertical sidewalls (Fu et al., 2009; Zhang et al., 2009). Deep reactive ion etching (DRIE) is an extension of RIE that enables high rate etching of deep and narrow structures. DRIE offers better selectivity and process controllability than RIE. DRIE can fabricate microstructures in silicon having vertical and smooth sidewalls, which are frequently required in various micro-electro-mechanical systems (MEMS) applications, such as micro-actuator, micro-accelerometer, pressure sensors and through-silicon via technology (Clerc et al., 1998; Franssila et al., 2000). The DRIE reactors have two RF generators for independent control of plasma generation and ion bombardment. Typical etch products include $\mathrm{SiF}_{4}$, $\mathrm{SiCl}_{4}, \mathrm{NF}_{3}, \mathrm{WF}_{6}, \mathrm{AlCl}_{3}$ when silicon or metals are etched with $\mathrm{SF}_{6}, \mathrm{CF}_{4}, \mathrm{Cl}_{2}, \mathrm{BCl}_{3}, \mathrm{SiCl}_{4}$. The parameters affecting the DRIE process are etchant gases, flow rate of chosen gases, RF power, bias voltage, process pressure and temperature (Hooda et al., 2010). $\mathrm{SF}_{6}$ is the mostly used etch gas in the DRIE etching of silicon (Dixit and Miao, 2008; Legtenberg et al., 1995). Common passivation gases used in DRIE are $\mathrm{C}_{4} \mathrm{~F}_{8}$ and $\mathrm{CHF}_{3}$ (Mizuhata et al., 2008; Lee et al., 2008).

In the present study new, simple and low-cost MFCA structures have been designed and fabricated. Dimensions of MFCA structures were designed as per the radius of deflection of the incoming charged particle (electrons), which has not been reported earlier in the literature. After the design, these MFCA structures were fabricated in silicon substrate. UV-lithography process was utilised for the fabrication of micro-Faraday cup structures in photoresist using a low-cost ultra violet-light emitting diode (UV-LED) lithography system. Further, these structures in photo-resist were utilised as mask in DRIE to create final structures in silicon.

\section{Design of MFCA structure}

Design of MFCA structure includes the calculation of dimensions such as width (opening), spacing (pitch). These parameters are based on the 'radius of deflection' of incoming charge particles (ions).

Radius of deflection is the radius through which the charged particle deflects under the influence of applied magnetic field. Width and spacing between the cups can be decided by the analysis of radius of deflection for various charged particles in certain range of accelerating potential and magnetic field. 
For finalising the geometrical parameters, radius of deflection of the incoming charge particles was calculated after considering the application in mass spectrometry (Darling et al., 2002). The following formula gives the values of radius of deflection $(R)$.

$$
R=\frac{\sqrt{2 m E}}{q B}
$$

where $B=$ strength of magnetic field (Tesla), $m=$ mass of the charged particle $(\mathrm{kg})$, $q=$ charge value of charged particle (coulomb) and $E=$ accelerating potential (volts).

Figure 1 shows variation of $R$ for different incoming ions under the influence of magnetic field, their mass values and charge values. Width of the cup, i.e., opening of the cup in case of top view, is the most important design parameter in the design of the MFCAD structure. The width should be small enough so that it should trap and detect smallest charged particle. This also means that it should be able to resolute between two smallest charged particles. The width as well as spacing will determine the resolution between two incident ions.

Figure 1 Schematic of cross-section of micro-Faraday cups with radius of deflection $(R)$ of charged particles

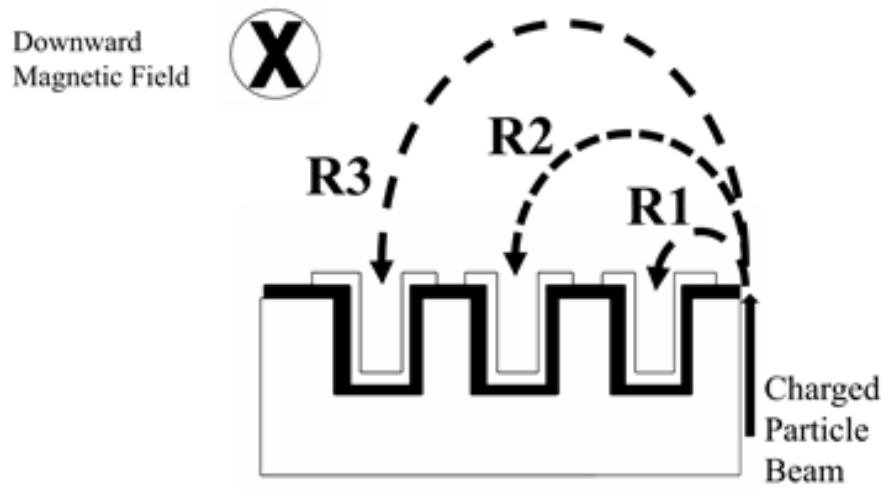

After the width, the major dimension is spacing of gap between the two cups. The spacing will determine the resolution between two incident ions. In order to trap and detect all charged particles, the spacing should be less or equal to the width. The number of cups will determine the range of detection. The number of cups should be in large number to detect all the incoming charge particles.

Electron particles were considered as the charged particles which we can detect using MFCA. ' $R$ ' value [see equation (1)] for electron at $500 \mathrm{~V}$ accelerating voltage was found to be $0.75 \mathrm{~mm}$ and at $3,700 \mathrm{~V}$ accelerating voltage was $2.0522 \mathrm{~mm}$. So the total linear dimension $(L)$ is given by:

$$
L=2 \times\left(R_{1}-R_{2}\right)
$$

where $R_{1}$ and $R_{2}$ are the radius of deflection at $3,700 \mathrm{~V}$ and $500 \mathrm{~V}$, respectively and were calculated as $2.0522 \mathrm{~mm}$ and $0.75 \mathrm{~mm}$ respectively. The finalised linear dimension was $2.604 \mathrm{~mm}$ (see Figure 2); hence all the cup structure dimension should be within 
$2.604 \mathrm{~mm}$. So finally the MFCAD dimensions were chosen based on the design calculations and limitations of the micro-fabrication techniques (see Table 1).

Figure 2 Dimensions of the MFCA structure with 2D and 3D views (all dimensions are in $\mathrm{mm}$ ), (a) dimensions (b) cross-sectional view (c) 3D view (d) 3D cross-sectional view

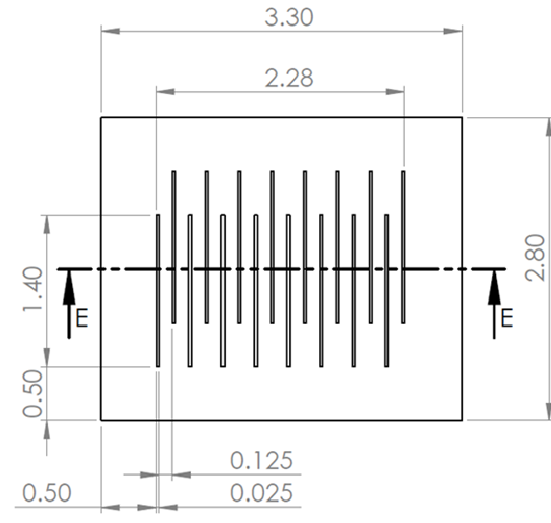

(a)

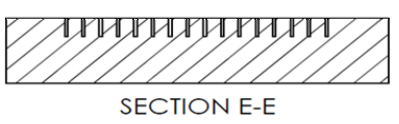

(b)

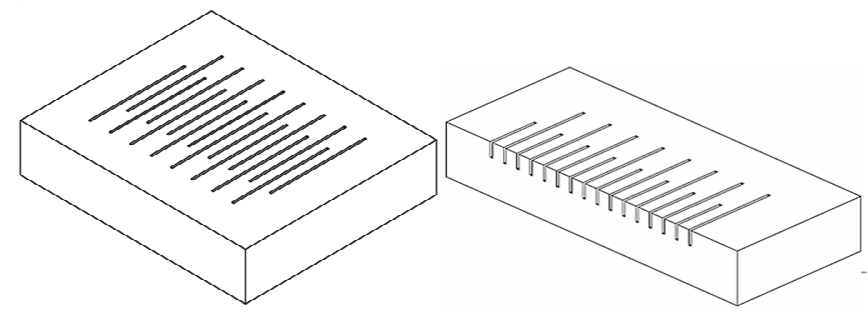

(c)

(d)

Table 1 MFCA structure dimensions

\section{Features}

No. of cups $(N)$

Cup length $(L)$

Width $(W)$

Spacing between two cups $(S)$
Cup dimensions

16

$1.4 \mathrm{~mm}$

$25 \mu \mathrm{m}$

$125 \mu \mathrm{m}$

\section{UV lithography setup}

For micro/nano patterning micro FCA structure in photoresist (AZ4903), UV lithography systems are used. These systems are based on mercury lamp sources for exposure. In MEMS, mercury-lamp-based UV lithography has been further improvised to use the light emitting diode sources - LEDs that emit near ultraviolet rays (Kim et al., 2011). For carrying out the photo-lithography, the following setup (see Figure 3) was used which consist of following sub parts. 
Figure 3 UV-LED lithography system

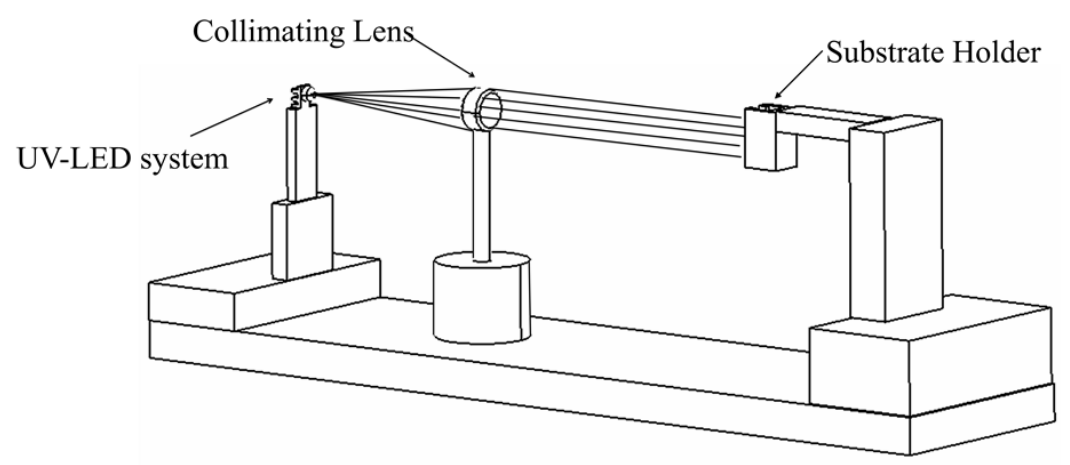

\section{$3.1 \quad U V$-LED exposure system}

The conventional exposure system, which is part of the commercial mask aligner equipment, are very much costly. In our system, UV-LED source was utilised as exposure unit, which was having a very less cost. The UV-LED with heat sink is shown in the Figure 4.

The photo-resist coated substrates were exposed under the UVLED system. Exposure time for the resist should be optimised according to the power of the UV-LED system. The dose given to substrate would also depend on the thickness and the type of photo-resist. The exposure time may be calculated as: exposure dose $=$ lamp power $\times$ exposure time. Exposure time was observed to be 10 seconds with exposure dose of $255.66 \mathrm{~mJ} / \mathrm{cm}^{2}$. For exposure source; the wavelength should be as short as possible because if the wavelength is large then the energy of exposure will be less. Thus the dose falling on the photo-resist will be less and insufficient to break the bonds of the photo-resist. Basically when UV light leads to chemical changes in photo-resist which is coated on the substrate these chemical changes lead to breakage of polymers into the monomers (for positive PR). Table 2 shows the standard parameters of UV-LED source used in the lithography.

Figure 4 UV-LED systems with heat sink

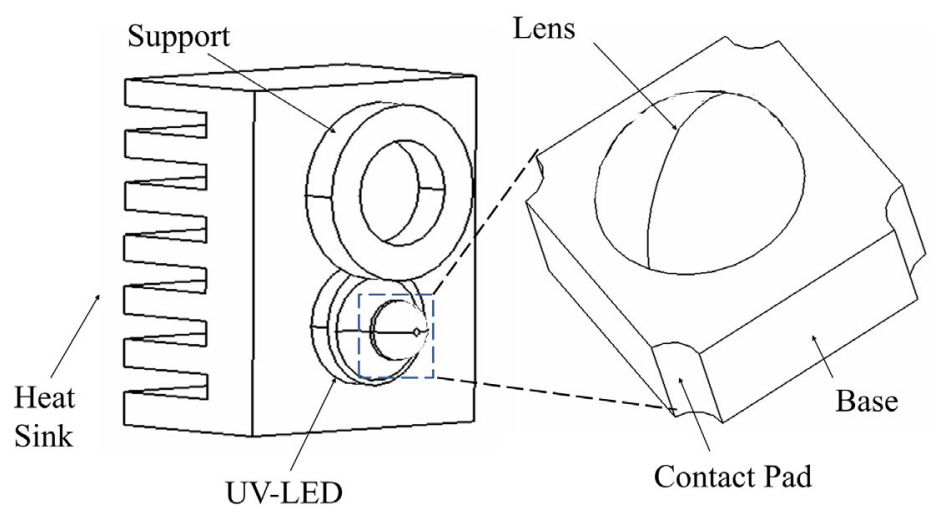


Table 2 Standard parameters for UV-LED source

\begin{tabular}{lc}
\hline Properties & Values \\
\hline Wavelength & $405 \mathrm{~nm}$ \\
Power & $5 \mathrm{~W}$ \\
Size & $4.4 \mathrm{~mm} \times 4.4 \mathrm{~mm}$ \\
Thermal resistance & $4.2^{\circ} \mathrm{C} / \mathrm{W}$ \\
\hline
\end{tabular}

\subsection{Lens system for collimation of the light}

UV-LED source was not well collimated and filtered wavelength was not available. Hence for collimated light source, a plano-convex lens system was selected based on db-OPTIC software simulation (see Figure 5). The collimation of the UV light using lens ensures lower tapering in the sidewall of produced microstructures. Using db-OPTIC software, plano-convex lens parameters were formulated, as shown in Table 3.

Figure 5 Lens design in db-OPTIC software
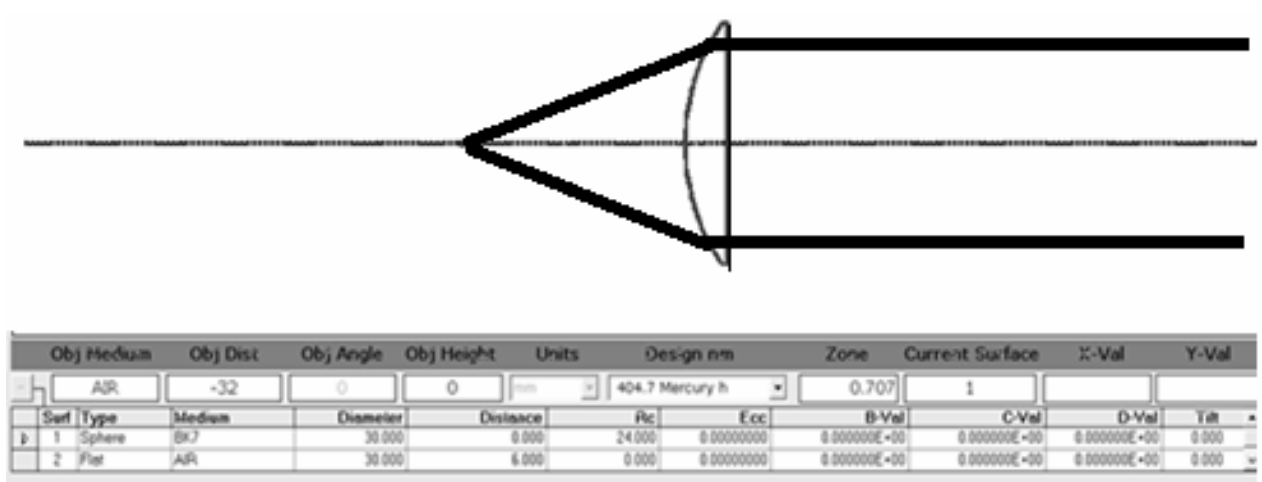

\begin{tabular}{|c|c|c|c|c|c|c|}
\hline Image & Destance & Aberration & Yalue & Tolerance & Otrer & Valow \\
\hline Faved ! & $41313 \times 01$ & Merpes Sphaical UR & & 204 & Secondey'seectin & \\
\hline Nopinal' & c)esse & Zons Sphences LUK & & 52303 & Feldciantres & 00000 \\
\hline Zoned $1 x$ & vasex & $\cos$ & & coess & Loters Colar & 00000 \\
\hline U (Pu) & (xt2ates) & Tangents Coms & & (an1) & Enche Dienerer & $\mathbf{x}$ \\
\hline Focalleng & $5 \times 9$ & Dutution (N) & es & 10 & Fruncer & in \\
\hline
\end{tabular}

Table 3 Selected parameters for collimating lens

\begin{tabular}{lc}
\hline Design parameter & Value \\
\hline Lens type & Plano-convex \\
Diameter of lens & $50 \mathrm{~mm}$ \\
Radius of curvature & $41 \mathrm{~mm}$ \\
Focal distance & $41 \mathrm{~mm}$ \\
Object distance (light source) & $35 \mathrm{~mm}$ \\
Medium & Air \\
Light source and wavelength & Helium d $(587 \mathrm{~nm})$ \\
\hline
\end{tabular}




\subsection{Substrate holding system}

Substrate holding system consists of a L-shaped stand, a slot at the front end, which mainly holds the substrate, glass plate and photo mask (gelatine mask). It was made up of an aluminium sheet. Generally, the substrate and photo mask were kept in close connection as contact type photolithography. To improve the fine contact and to reduce the air gap between the mask and the substrate, the substrate and photo mask was held tightly between two glass plates for suitable exposure (see Figure 6). It can hold the UV photo mask size of smaller dimension $1 \mathrm{~mm} \times 1 \mathrm{~mm}$ to maximum about $10 \mathrm{~mm} \times 10 \mathrm{~mm}$.

Figure 6 Arranged substrate (a) actual (b) cross-section
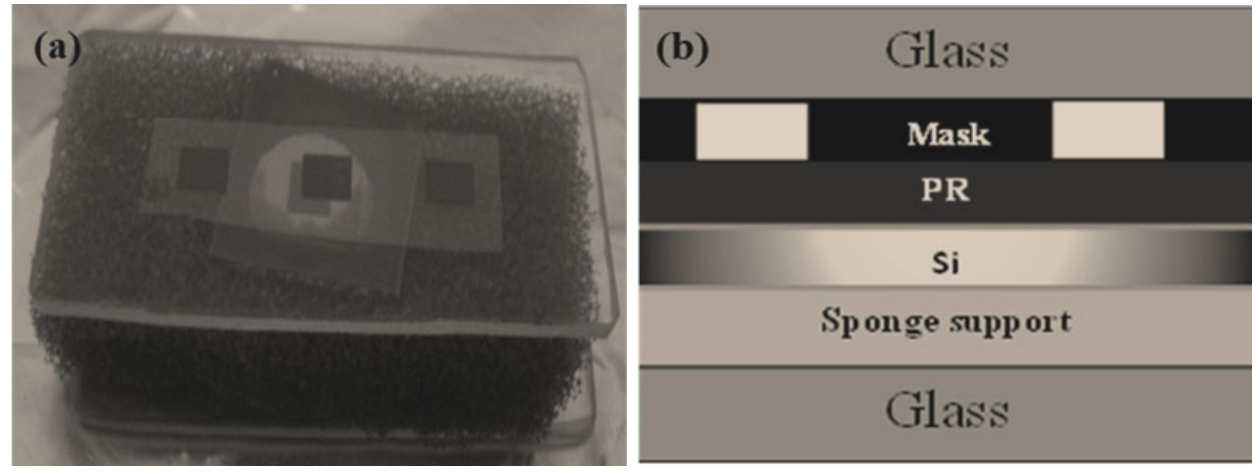

Properly arranged substrate is shown in Figure 6, was positioned in the L-shaped stand without disturbing the contact of substrate and photo mask. The fixture (where the arranged substrate was placed) was in close tolerance with arranged substrate. This ensured close contact with minimum air gap.

Figure 7 shows the steps followed for putting the arranged substrate in the stand and finally positioned substrate.

Figure 7 (a) Positioning the arranged substrate in the holder (b) Final position of the arranged substrate

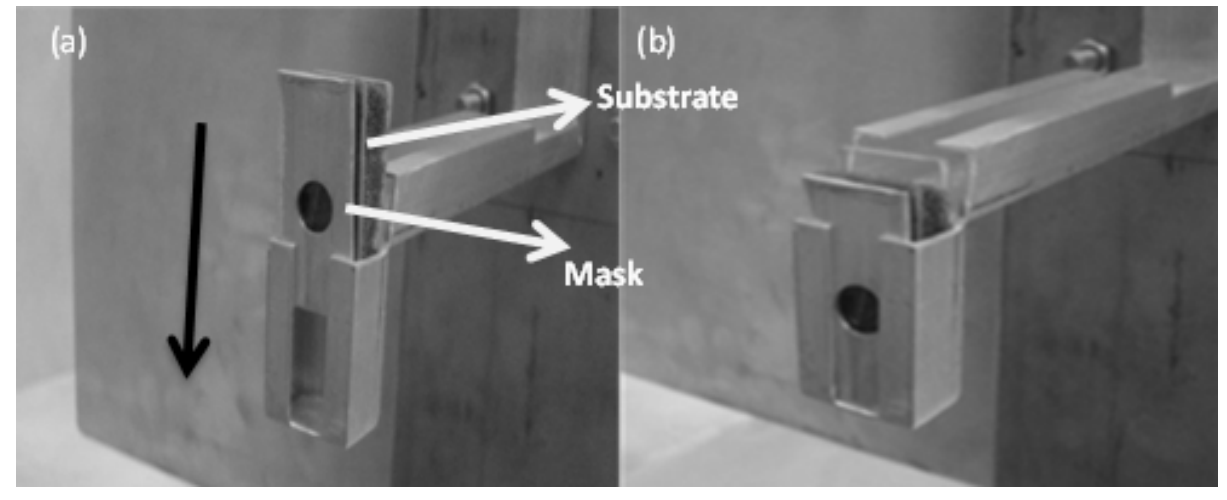




\section{Experimental results and discussion}

Following flowchart (Figure 8) shows the experimental process flow carried out. It mainly includes optimisation of the UV lithography process followed by DRIE process.

Figure 8 Fabrication process flowchart

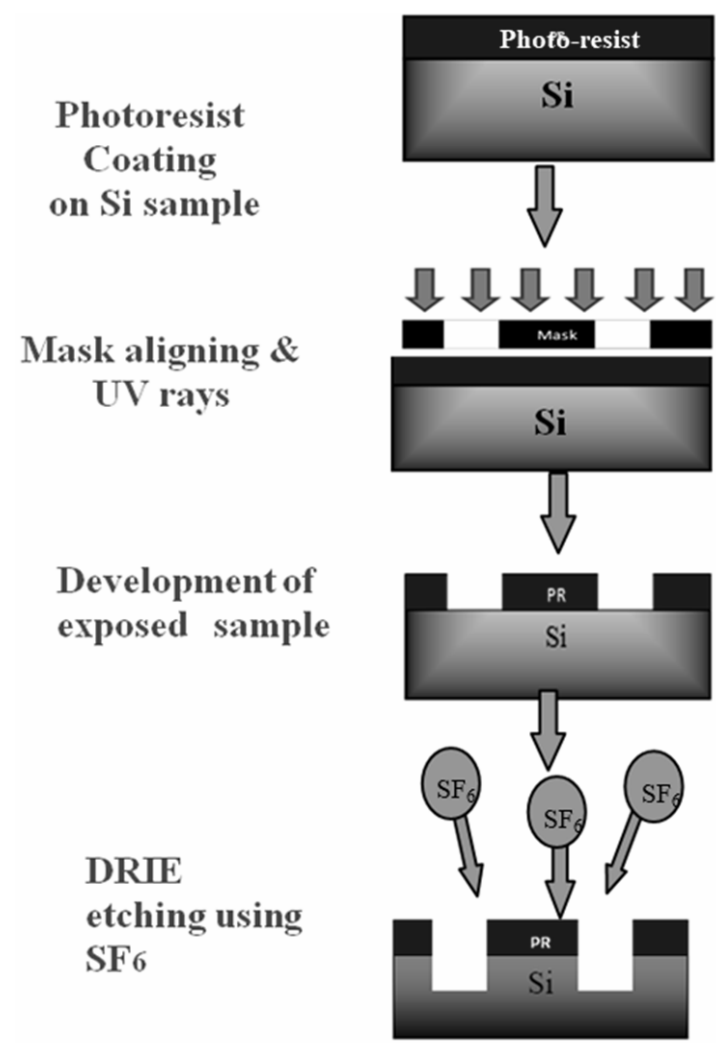

\subsection{Cleaning of the substrate}

Silicon wafer substrate (n-type) having dimensions $1 \mathrm{~cm} \times 1 \mathrm{~cm}$ with the thickness of $500 \mu \mathrm{m}$ was cleaned before performing the experiments. The silicon samples were ultra-sonicated in the ultrasonic cleaner for 5 minutes to remove the organic impurities and contaminants.

\subsection{Photoresist (PR) coating}

Positive PR AZ-4903 was coated over cleaned Si-wafer. Spin coater (MS-A100, Mikasa Opticoat spin coater was used to accomplish PR coating of uniform thickness. Spin coater comprise with rotor chuck, on which Si wafer was placed by using vacuum pump. A program with 3,000 rpm for 45 second was operated to get pre-optimised $14 \mu \mathrm{m}$ thickness. The speed and time parameters for thickness of $14 \mu \mathrm{m}$ were selected from data 
sheet of AZ-4903. The PR coated sample was prebaked on precision hot plate at $110^{\circ} \mathrm{C}$ for 12 minutes. Pre-bake or soft-bake was required to remove remaining solvent and built-in-stress.

\subsection{UV-lithography for photo-resist patterning}

UV-lithography was used for creating (patterning) the desired cup structures in the photo-resist, which has ultimately acted as a mask in the DRIE etching. During the UV-light exposure the photon energy weakens the molecular bond in the positive photoresist. The exposed sample was then dipped in the developer solution for development process. During this, the photoresist was removed from the areas where the bonds got weakened. After prebaking, UV light exposure was done by simple and low cost UV-LED lithography setup. Exposure time was varied from $15 \mathrm{~min}$ to $10 \mathrm{sec}$. It was followed by development in AZP4903 developer. Development time was varied from $2 \mathrm{~min}$ to $6 \mathrm{~min}$. The development solution used was the mixture of AZP4903 developer $(15 \mathrm{ml})$ and DI water $(45 \mathrm{ml})$ having 1:3 ratio.

Figure 9 shows the variation of cup width patterned in photoresist with respect to exposure time. Exposure time of 10 seconds was based on the UV-LED power and exposure dose for the required area. Total power of UV-LED is $850 \mathrm{~mW}$. Considering diffraction losses $80 \%$ to $85 \%$ of total power was assumed to be utilised. Based on datasheet of AZ4903 photo-resist datasheet exposure dose of less than $400 \mathrm{~mJ} / \mathrm{cm}^{2}$ is required for getting the features line-width of greater than $23 \mu \mathrm{m}$ in photo-resist having $14 \mu \mathrm{m}$ thicknesses. So based on these values, exposure time of $10 \mathrm{sec}$ was found to be appropriate in order get the required feature size of $25 \mu \mathrm{m}$ in the photoresist.

The structural characterisation was carried out by optical microscope after UV lithography (see Figure 10). Table 4 shows the comparison of UV-LED-based lithography and mercury lamp-based lithography. One of the main advantage with UV-LED exposure system is the single dominant wavelength of $405 \mathrm{~nm}$, which is suitable for fabricating micro features precisely. Spectral radiance of UV-LED is also more than the mercury lamp (Hölz et al., 2016).

Table 4 Comparison of two exposure sources for UV Lithography

\begin{tabular}{|c|c|c|}
\hline Parameters & $U V-L E D$ & Mercury lamp \\
\hline Wavelength produced & Single dominant peak $(405 \mathrm{~nm})$ & $\begin{array}{c}\text { Multiple peaks } \\
(435 \mathrm{~nm}, 405 \mathrm{~nm}, 365 \mathrm{~nm})\end{array}$ \\
\hline Compactness & Very compact & Bulky \\
\hline Source cost & $5,000 \mathrm{INR}$ & $35,000 \mathrm{INR}$ \\
\hline $\begin{array}{l}\text { Ancillary systems } \\
\text { (supply, lens, stands) }\end{array}$ & Simple & Complex \\
\hline Development time & $16 \mathrm{~min}$ & $6 \mathrm{~min}$ \\
\hline $\begin{array}{l}\text { Exposure time of MFCA } \\
\text { structure of } 25 \mu \mathrm{m}\end{array}$ & $10 \mathrm{sec}$ & $2 \mathrm{~min}$ \\
\hline
\end{tabular}

Following graph (Figure 11) shows the width of cup structures at different exposure times. Photoresist pattern width of $25 \mu \mathrm{m}$ was achieved at 10 seconds of exposure time. Maximum photoresist pattern width of $65 \mu \mathrm{m}$ was obtained at 125 seconds. 
Figure 9 Variation of width of cup as exposure time is varied from (a) $125 \mathrm{sec}$ (b) $100 \mathrm{sec}$ (c) $50 \mathrm{sec}$ (d) $40 \mathrm{sec}$ (e) $30 \mathrm{sec}$ (f) $10 \mathrm{sec}$
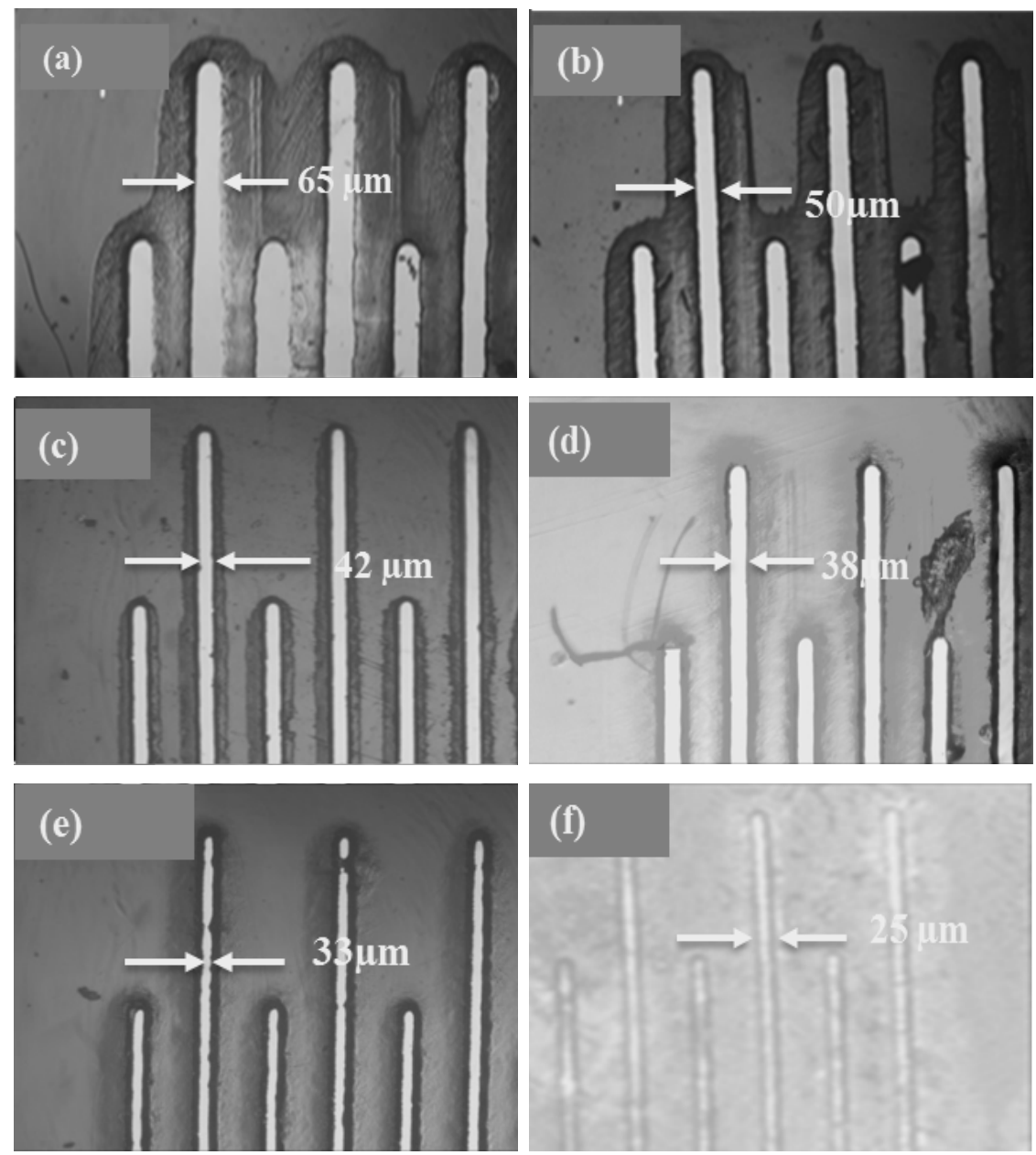

Figure 10 Optical micrograph of optimised MFCA after UV lithography at (a) 5× (b) $10 \times$ magnification

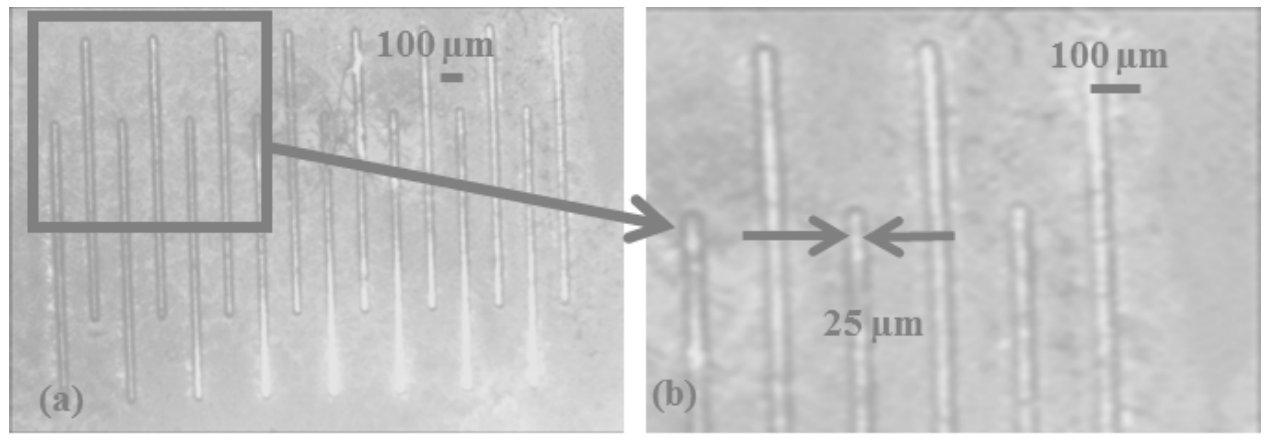


Figure 11 Variation of cup width with respect to exposure time for UV lithograph

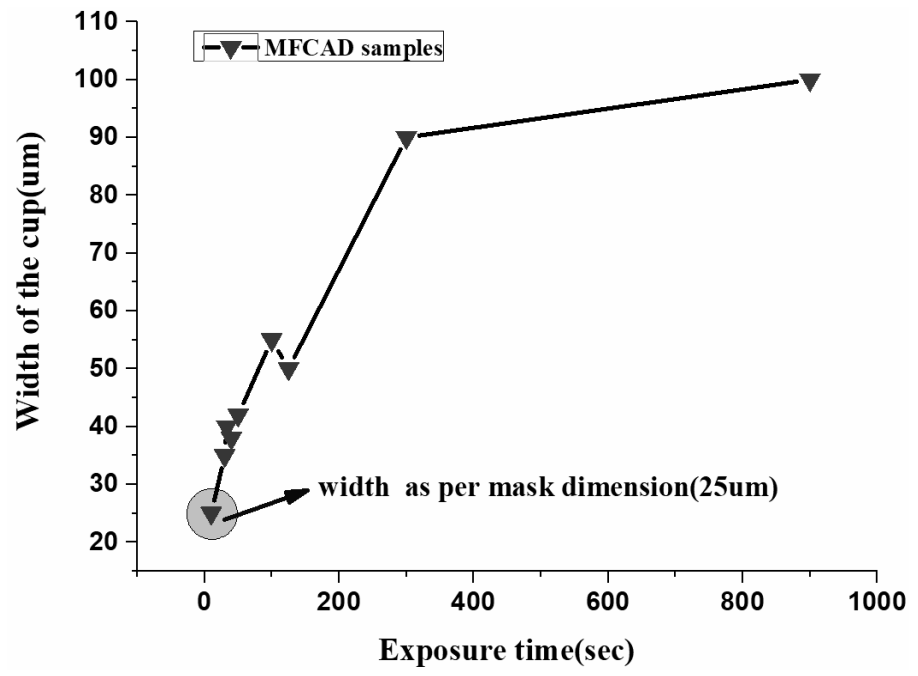

\subsection{DRIE (Bosch process)}

A successfully developed MFCA pattern in the photoresist (AZ4903) on silicon substrate was further used in the DRIE process to get the final structure on silicon substrate along with morphological characterisations using FESEM and confocal microscope. DRIE (Bosch process) is used to get anisotropic or straight walled trenches in silicon by $\mathrm{SF}_{6}$ plasma and by protecting the trench side-walls with a Teflon-like polymer deposited in between the two consecutive etch steps. Bosch process is a time-multiplexed plasma etching process. The $\mathrm{SF}_{6}+\mathrm{O}_{2}$ gas chemistry was used to etch silicon. The plasma gas was then switched to $\mathrm{C}_{4} \mathrm{~F}_{8}$ gas for a conformal coverage of via sidewalls with a layer of Teflon like polymer layer. After the DRIE process the remaining photo-resist was stripped off using acetone.

Figure 12 Oxford PlasmaLab100 DRIE machine

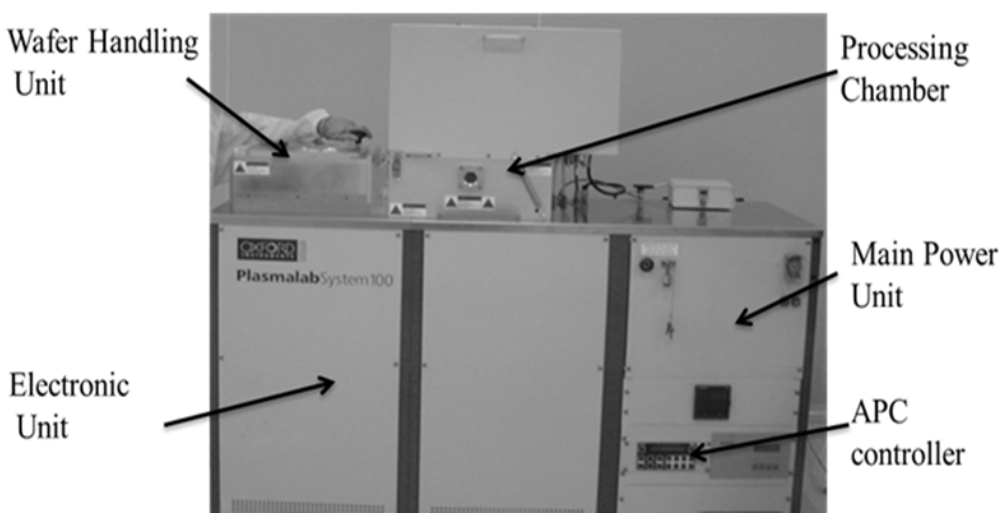


For performing DRIE etching, oxford plasma lab SYSTEM 100 machine was used (see Figure 12). Since the optimised gas chemistry was not obtained earlier for the available system, some experiments were performed for checking the depths can be achieved. Three samples were DRIE etched and discussed further. Table 5 shows the various parameters of the DRIE process. The flow rate of etch gases $\left(\mathrm{SF}_{6}\right)$ and passivation gas $\left(\mathrm{C}_{4} \mathrm{~F}_{8}\right)$ were kept constant. Inductively coupled plasma (ICP) power and radio-frequency (RF) power values were selected as $500 \mathrm{~W}$ and $20 \mathrm{~W}$ respectively. First sample was etched with the DRIE parameters shown in the Table 5. The total time for the etching was 5.67 minutes, which includes the etch cycle of 2.33 minutes and passivation cycle of 3.33 minutes. SEM microscope images of DRIE etched cup structures are shown in Figure 13. The depth achieved by DRIE was $2.5 \mu \mathrm{m}$ in this case. Low depth of cup was due to low etch cycle time .For low etch cycle time the etch rate was low. The sidewalls were perfectly vertical. The bottom surface of the cup was found to be rough and has irregular shaped features which have sharp peaks, also known as black silicon or silicon grass. It has the typical shape of nano-pillars, which was a by-product of the DRIE process. Formation of the silicon grass during RIE was happened due to a local deviation of the Si etch rate. This deviation in etching rate can be initiated by Si surface itself, for example inhomogeneous oxide layer or partly removed native oxide (Chow et al., 1987). Silicon grass was also formed due to the residual passivation layer of $\mathrm{C}_{4} \mathrm{~F}_{8}$. When the Teflon like polymer layer was not being removed completely, it locally protect the underlying silicon substrate and thus causing sharp needle like structure, known as silicon grass. This effect is known as micro-masking and mainly arises due to extreme passivation conditions and shorter etch cycle time (Dixit and Miao, 2006; Jung et al., 2010).

Table 5 DRIE process parameters values

\begin{tabular}{|c|c|c|c|c|c|c|}
\hline \multirow[b]{2}{*}{ Process parameters } & \multicolumn{2}{|c|}{ Sample no. 1} & \multicolumn{2}{|c|}{ Sample no. 2} & \multicolumn{2}{|c|}{ Sample no. 3} \\
\hline & $\begin{array}{l}\text { Etch } \\
\text { cycle }\end{array}$ & $\begin{array}{c}\text { Passivation } \\
\text { cycle }\end{array}$ & $\begin{array}{l}\text { Etch } \\
\text { cycle }\end{array}$ & $\begin{array}{c}\text { Passivation } \\
\text { cycle }\end{array}$ & $\begin{array}{l}\text { Etch } \\
\text { cycle }\end{array}$ & $\begin{array}{c}\text { Passivation } \\
\text { cycle }\end{array}$ \\
\hline $\mathrm{SF}_{6}$ flow $(\mathrm{sccm})$ & 20 & 1 & 20 & 1 & 20 & 1 \\
\hline $\mathrm{O}_{2}$ flow $(\mathrm{sccm})$ & 5 & 1 & 5 & 1 & 5 & 1 \\
\hline He flow $(\mathrm{sccm})$ & 10 & 10 & 10 & 10 & 10 & 10 \\
\hline $\mathrm{C}_{4} \mathrm{~F}_{8}$ flow (sccm) & 1 & 30 & 1 & 30 & 1 & 30 \\
\hline RF power (W) & 20 & 20 & 20 & 20 & 20 & 20 \\
\hline ICP power $(\mathrm{W})$ & 500 & 500 & 500 & 500 & 500 & 500 \\
\hline Pressure (mTorr) & 30 & 30 & 30 & 30 & 30 & 30 \\
\hline Cycle time (s) & 7 & 10 & 7 & 10 & 7 & 10 \\
\hline No. of cycles & 20 & 20 & 250 & 250 & 320 & 320 \\
\hline Total time (minutes) & 2.33 & 3.33 & 29.17 & 41.67 & 37.33 & 53.33 \\
\hline Average depth $(\mu \mathrm{m})$ & \multicolumn{2}{|r|}{2.5} & \multicolumn{2}{|r|}{10} & \multicolumn{2}{|r|}{16} \\
\hline
\end{tabular}

Second sample was DRIE etched for etch cycle of 29.17 minutes and passivation cycle of 41.67 minutes. SEM and confocal microscope images of DRIE etched cup structures were shown in Figure 14 the depth achieved by DRIE was $10 \mu \mathrm{m}$. Since the etch cycle was increased the more fluorine radicals will attack the silicon bonds and forms volatile compound $\mathrm{SiF}_{4}$. Hence, the more depth was achieved with higher etch cycle time. The 
surface quality of the etched cup did not improved much at this increased etch time and silicon grass was formed in small amounts.

Figure 13 SEM images of the DRIE etched sample no. 1 (a) 16 cups (b) $100 \times$ magnification (c) depth profile (see online version for colours)

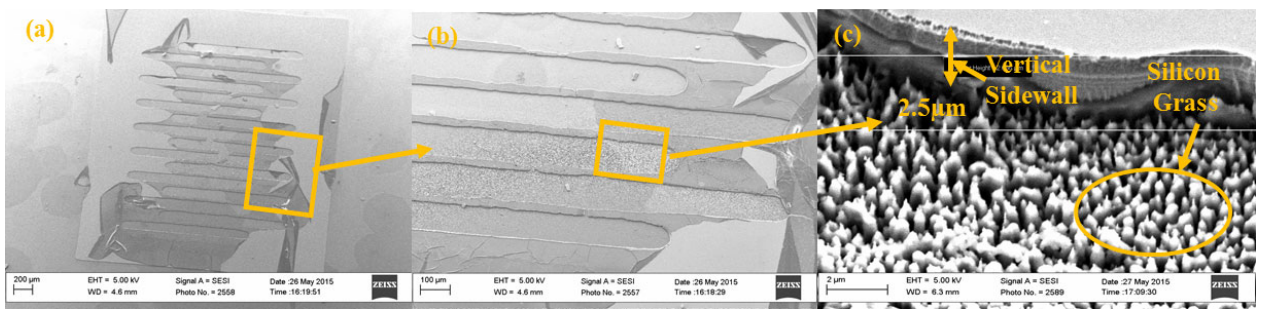

Figure 14 SEM and confocal microscope images of the DRIE etched sample no. 2 (a) 16 cups (b) $100 \times$ magnification (c) depth profile (d) top view (e) 3D view (f) variation in depth profiles (see online version for colours)

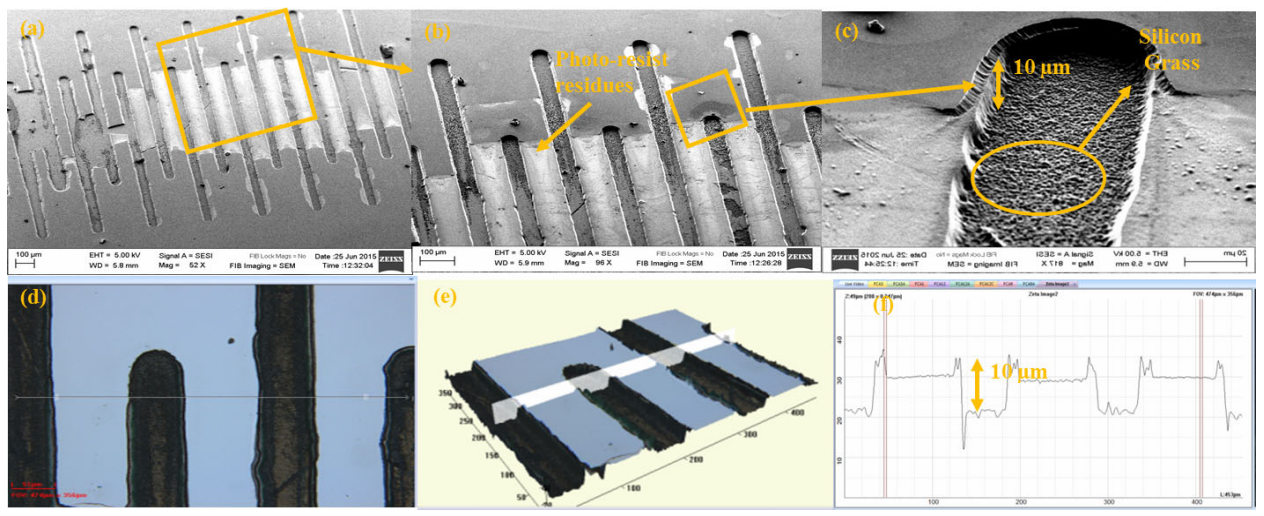

Figure 15 SEM and confocal microscope images of the DRIE etched sample no. 3 (a) 16 cups (b) $100 \times$ magnification (c) depth profile (d) top view (e) $3 \mathrm{~d}$ view (f) variation in depth profiles (see online version for colours)

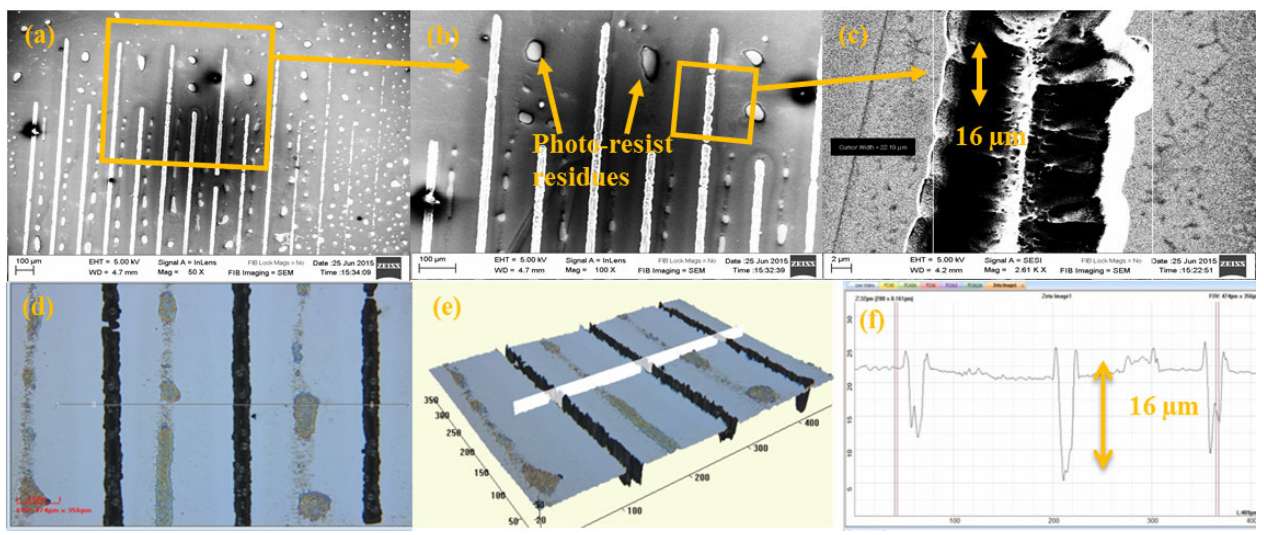


Sample 3 was etched for etch cycle of 37.33 minutes and passivation cycle of 53.33 minutes. The average depth achieved by DRIE was $16 \mu \mathrm{m}$. Increment in depth attributed to the higher amount of material removal due to longer etch cycle time. By analysing the SEM images and confocal microscope images (see Figure 15), it was observed that silicon grass formation was reduced and therefore the bottom surface quality was improved. As mentioned earlier, the micro-masking phenomenon of grass formation at the bottom of the DRIE etched cup was severe at shorter etch cycle time. In order to minimise this effect etch cycle time was increased, which led to removal of bottom passivation layer of polymer in larger extent. There was a little variation of 1 to $3 \mu \mathrm{m}$ in depth of cup achieved for each cup. This may be due the fact that the development of photo-resist AZ4903 mask was non-uniform during the UV lithography.

Figure 16 (a) Size of overall MFCA (b) Variation in cup depth vs. etch cycle time (c) Variation in cup sidewall angle vs. etch cycle time
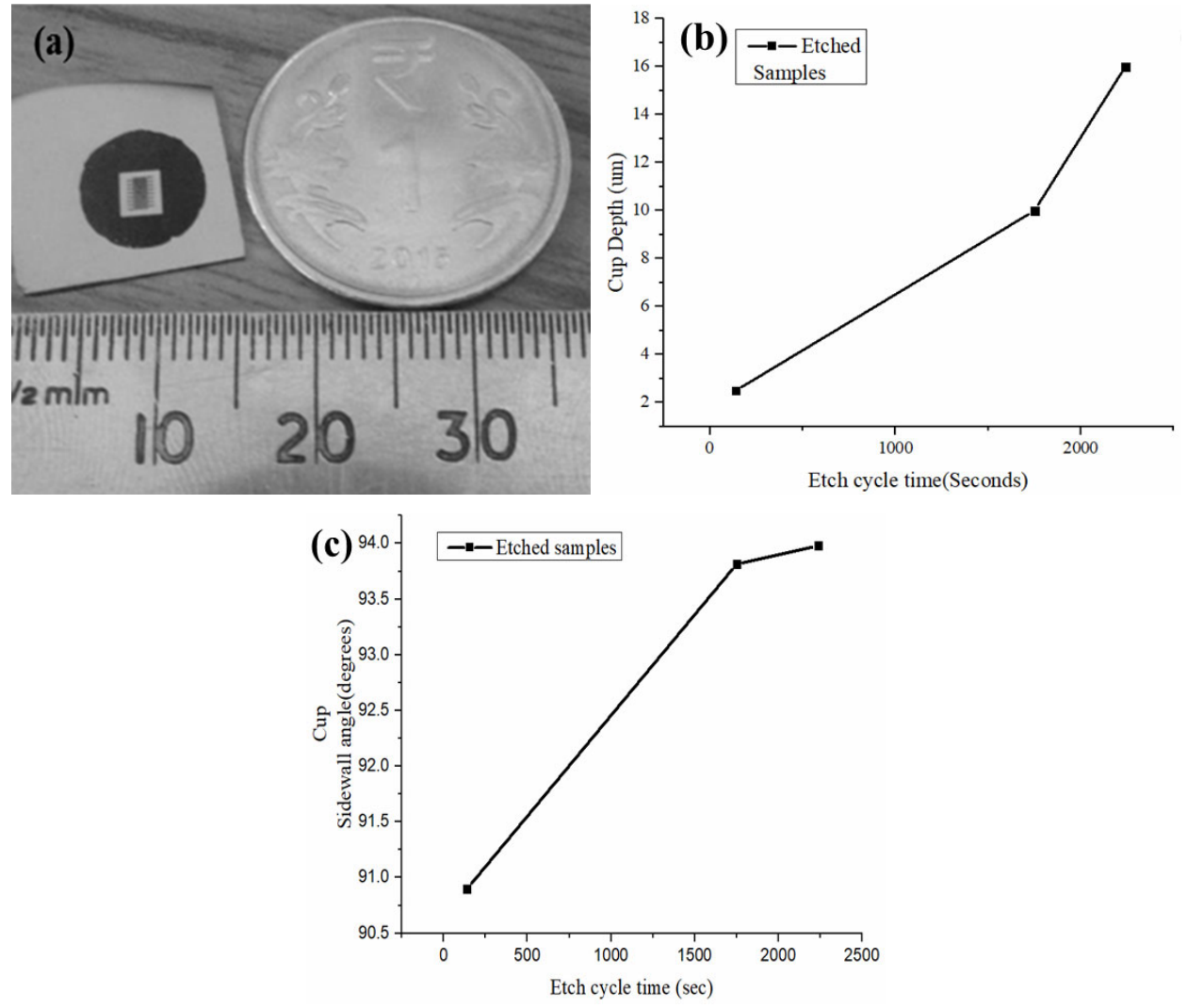

Figure 16(a) shows the overall size of MFCA structure in silicon after DRIE processing. The variation in cup depth with respect to etch cycle for the DRIE etched silicon substrates, is shown in Figure 16(b). The graph indicates the increase in the MFCA cup depth with respect to etch cycle time. As the etch cycle time was increasing the supply of $\mathrm{SF}_{6}$ etching gas was more, which leads faster rate of silicon material removal. For etch cycle time of 37.33 minutes, cup depth was observed to $16 \mu \mathrm{m}$, which was the maximum depth achieved. Figure 16(c) shows the variation of cup sidewall angle with respect to 
etch cycle time. At etching cycle time of $140 \mathrm{~s}, 1,750 \mathrm{~s}$ and 2,239 s, cup sidewall angles were observed to be $90.9^{\circ}, 93.81^{\circ}$, and $93.97^{\circ}$, respectively. This increment in cup sidewall angle was due to the excess amount of etching species for higher etch time. So it can be concluded that etched cup profile was altered from the positive tapered cups to negative tapered cups, when the etch cycle time was increased. When the etching gas $\left(\mathrm{SF}_{6}+\mathrm{O}_{2}\right)$ was supplied for longer time, the quantity of etching radicals was found to be higher which led to increment in the lateral scallop formation. This ultimately increased the cups lateral dimension.

\section{Conclusions}

Fabrication of new and simple MFCA structures in silicon is reported in this paper. These $1 \times 16$ array cup structures have width (opening) of $25 \mu \mathrm{m}$ and spacing of $125 \mu \mathrm{m}$. For patterning these structures in photoresist, UV lithography was performed on low-cost and compact UV-LED lithography system exposure dose and exposure time was found to be $255.66 \mathrm{~mJ} / \mathrm{cm}^{2}$ and 10 seconds respectively. These developed patterns in the photoresist were used as masking layer for DRIE etching in silicon. In DRIE, etch rate was observed to be $10 \mu \mathrm{m} /$ hours. Faraday cups depth was found to be increased when etch cycle time was increased. Maximum cup depth was observed to $16 \mu \mathrm{m}$ at etch time of 2,239 sec. cups sidewall angle showed increment with respect to etch cycle time. Finally, the cup structures with width $25 \mu \mathrm{m}$ and depth $16 \mu \mathrm{m}$ were fabricated in silicon.

\section{Acknowledgements}

The authors wish to express their gratitude to Mrs. P. Tiwari, Mr. Mahendra Babu, Mr. Sudheer and Ms. Akshita Mishra from RRCAT, Indore for their help in measurement and characterisation.

\section{References}

Anasane, S. and Bhattacharyya, B. (2016) 'Investigation on micro-milling of through microslots on titanium by electrochemical micromachining', International Journal of Precision Technology, Vol. 6, Nos. 3-4, pp.231-248.

Birkinshaw, K. (2002) 'Mass spectrum measurement using a one-dimensional focal plane detector', International Journal of Mass Spectrometry, Vol. 215, Nos. 1-3, pp.195-209.

Bower, C.A., Gilchrist, K.H., Lueck, M.R. and Stoner, B.R. (2007) 'Micro fabrication of fine-pitch high aspect ratio Faraday cup arrays in silicon', Sensors and Actuators A: Physical, Vol. 137, No. 2, pp.296-301.

Chow, T.P., Maciel, P.A. and Fanelli, G.M. (1987) 'Reactive ion etching of silicon in $\mathrm{CCI}_{4}$ and HCI plasmas', Journal of Electrochemical Society, Vol. 134, No. 5, pp.1281-1286.

Clerc, P.A., Dellmann, L., Jeanneret, S., Racine, G.A., Roth, S., Staufer, U., Stebler, C., Thiebaud, P. and Rooij, N.F.D. (1998) 'Advanced deep reactive ion etching: a versatile tool for microelectromechanical systems', Journal of Micromechanics and Microengineering, Vol. 8, No. 4, pp.272-278.

Darling, R., Bhat, K.N. and Chen, C.N. (2002) 'Micro-machined Faraday cup array using deep reactive ion etching', Sensors and Actuators A: Physical, Vol. A95, Nos. 2-3, pp.84-93. 
Darrow, D.S., Cecil, F.E., Kiptily, V., Fullard, A. and Murari, A. (2010) 'Observation of alpha particle loss from JET plasmas during ion cyclotron resonance frequency heating using a thin foil Faraday cup detector array', Review of scientific Instruments, Vol. 81, No. 10, p.D330.

Dixit, P. and Miao, J. (2006) 'Effect of $\mathrm{SF}_{6}$ flow rate on the etched surface profile and bottom grass formation in deep reactive ion etching process', Journal of Physics: Conference Series, Vol. 34, No. 1, pp.577-582.

Dixit, P. and Miao, J. (2008) 'High aspect ratio vertical through-vias for 3D MEMS packaging applications by optimized three-step deep RIE', Journal of The Electrochemical Society, Vol. 155, No. 2, pp.H85-H91.

Eiceman, G.A. and Stone, J.A. (2004) 'Ion mobility spectrometers in national defense', Analytical Chemistry, Vol. 76, No. 21, pp.390A-397A.

Franssila, S., Kiihamaki, J. and Karttunen, J. (2000) 'Etching through silicon wafer in inductively coupled plasma', Microsystem Technologies, Vol. 6, No. 4, pp.141-144.

Fu, Y.Q., Colli, A., Fasoli, A., Luo, J.K., Flewitt, A.J., Ferrari, A.C. and Milne, W.I. (2009) 'Deep reactive ion etching as a tool for nanostructure fabrication', Journal of Vacuum Science and Technology B, Vol. 27, No. 3, pp.1520-1526.

Gopikrishnan, A., Kanthababu, M., Mathew, N.T., Gowri, S. and Balasubramaniam, R. (2015) 'Multi-objective optimisation in the microturning of cobalt chromium with coated and uncoated tools using the grey relational analysis', International Journal of Precision Technology, Vol. 5, No. 1, pp.44-61.

Hölz, K., Lietard, J. and Somoza, M.M. (2016) 'High-power 365 nm UV LED mercury arc lamp replacement for photochemistry and chemical photolithography', ACS Sustainable Chemistry and Engineering, Vol. 5, No. 1, pp.28-834.

Hooda, M.K., Wadhwaa, M., Vermaa, S., Nayak, M.M., George, P.J. and Paul, A.K. (2010) 'A systematic study of DRIE process for high aspect ratio micro-structuring, Vacuum, Vol. 84, No. 9, pp.1142-1148.

Jain, V.K., Suthar, V. and Kulkarni, A.V. (2015) 'Fabrication of tapered micro-pillars on titanium alloy using electric discharge micromachining', International Journal of Precision Technology, Vol. 5, No. 2, pp.97-113.

Jung, K.B., Song, W., Lim, H. and Lee, C. (2010) 'Parameter study for silicon grass formation in bosch process', Journal of Vacuum Science and Technology B, Vol. 28, No. 1, pp.143-148.

Kim, J., Allen, M.G. and Yoon, Y.K. (2011) 'Computer controlled dynamic mode multidirectional UV lithography for 3D microfabrication', Journal of Micromechanics and Microengineering, Vol. 21, No. 3, pp.035003(1-14).

Knight, A.K., Sperline, R.P. and Hieftje, G.M. (2002) 'The development of a micro-Faraday array for ion detection', International Journal of Mass Spectrometry, Vol. 215, Nos. 1-3, pp.131-139.

Kovacs, G.T.A., Nadim, M. and Petersen, K.E. (1998) 'Bulk Micromachining of Silicon', Proceedings of the IEEE, Vol. 86, No. 8, pp.1536-1551.

Kumar, S., Hansda, B., Das, S., Doloi, B. and Bhattacharyya, B. (2017) 'Micro hole fabrication on quartz using ultrasonic micromachining process', International Journal of Precision Technology, Vol. 7, Nos. 2-4, pp.222-236.

Lee, H., Hung, C., Leng, C., Lian, N., Young, L., Yang, T., Chen, K. and Lu, C-Y. (2008) 'Etch defect characterization and reduction in hard-mask-based al interconnect etching', International Journal of Plasma Science and Engineering, Vol. 2008, No. 1, p.154035.

Legtenberg, R., Legtenberg, R., Jansen, H.V., de Boer, M.J. and Elwenspoek, M.C. (1995) 'Anisotropic reactive ion etching of siliconusing SF6/O2/CHF3 gas mixtures', Journal of the Electrochemical Society, Vol. 142, No. 6, pp.2020-2028.

Lorincik, J., Denton, M.B., Sperline, R.P., Young, E.T. and Williams, P. (2011) 'Testing of a micro Faraday cup array for ion detection in SIMS', Analytical Letters, Vol. 44, No. 6, pp.1050-1057. 
Madou, M.J. (2012) Fundamentals of Microfabrication and Nanotechnology, CRC Press Taylor and Francis Group, USA.

Mahalik, N.P. (2008) 'Principle and applications of MEMS: a review', International Journal of Manufacturing Technology and Management, Vol. 13, Nos. 2-4, pp.324-343.

Mizuhata, M., Miyake, T., Nomoto, Y. and Deki, S. (2008) 'Deep reactive ion etching (deep-RIE) process for fabrication of ordered structural metal oxide thin films by the liquid phase infiltration method', Microelectronic Engineering, Vol. 85, No. 2, pp.355-364.

$\mathrm{Ou}, \mathrm{K} ., \mathrm{Wu}, \mathrm{W} . \mathrm{I}$. and Selvaganapathy, P.R. (2010) 'Process design for reactive ion etching of silicones', International Journal of Abrasive Technology, Vol. 3, No. 2, pp.105-121.

Prokupek, J., Kaufman, J., Margarone, D., Krus, M., Velyhan, A., Krása, J., Burris-Mog, T., Busold, S., Deppert, O., Cowan, T.E. and Korn, G. (2014) 'Development and first experimental tests of Faraday cup array', Review of Scientific Instruments, Vol. 85, No. 1, p.013302.

Qu, H. (2016) 'CMOS MEMS fabrication technologies and devices', Micromachines, Vol. 7, No. 14, pp.1-21.

Scheidemann, A., Isakharov, A. and Darling, R. (2002) 'Faraday cup detector array with electronic multiplexing for multichannel mass spectrometry', Journal of Vaccume Science and Technology, Vol. 20, No. 3, pp.597-604.

Zhang, J., Huang, Q.A. and Li, W.H. (2009) 'Modelling and simulations of DRIE including a footing effect', International Journal of Computational Materials Science and Surface Engineering, Vol. 2, Nos. 3-4, pp.302-311. 